\title{
Análise Socioambiental do Médio Curso do rio Acaraú - CE
}

\author{
Socioenvironmental analy sis of the River Acaraú \\ MESQUITA $^{1}$, N. S.; SOUSA ${ }^{2}$, M. C.; CARACRISTI ${ }^{3}$, I.; DINIZ ${ }^{4}$, S. F. \\ natalia12_2011@hotmail.com
}

\begin{abstract}
Resumo
O manejo inadequado do solo no médio curso do rio Acaraú mostrou processos erosivos acentuados devido às ações humanas, como a remoção da vegetação (caatinga) para a implantação de pastagens e a agricultura. Com o objetivo de realizar uma análise socioambiental da planície fluvial do médio curso do rio Acaraú e levando em consideração os aspectos geomorfológicos, pedológicos e fluviais da planície fluvial do rio, desenvolvemos a referida pesquisa. A metodologia deste trabalho consistiu na utilização de mapas digitais gerados em ambiente SIG (Quantum Gis) e trabalho de campo para análise e identificação dos processos erosivos no médio Acaraú, localizado na região noroeste do Estado do Ceará. Com os resultados, foi possível avaliar e propor alternativas de uso sustentável, a partir de análises de mapas pré-existentes e trabalho de campo, em que foram verificadas a paisagem e as consequências causadas pelos impactos no ecossistema fluvial.
\end{abstract}

Palavras-chave: planície fluvial; sustentável; SIG.

\begin{abstract}
Inadequate management of soil in the middle course of the Acaraú River showed sharp erosion due to human actions, such as the removal of vegetation (caatinga) for the establishment of pastures and agriculture. With the goal of conducting a socio-environmental analysis of the fluvial plain of the middle course of the Acaraú River and taking into consideration the geomorphological, soil and river aspects of fluvial plain of the river. The methodology of this study consisted in the use of digital maps created in GIS environment (Quantum GIS) and field work to identify the erosive processes in the middle course of the Acaraú River, located in the northwestern region of the State of Ceará.

With the results, it was possible to evaluate and apply this tool for planning the physical environment, from analysis of digital maps and field work, in which were found the landscape and the consequences caused by impacts on the river ecosystem.
\end{abstract}

Keywords - fluvial plain; sustainable; GIS.

\section{INTRODUÇÃO}

Nos últimos anos, o meio ambiente tem enfrentado sérios problemas, ocasionados pelas ações antrópicas, como o uso indevido dos recursos hídricos e o desmatamento irregular de vegetações nativas. Todos esses fatores geram sérias consequências para a sociedade, e eles ocorrem na cidade de Santana do Acaraú/CE, por isso a importância de se trabalhar com esse tema, tão importante nos dias atuais. Esta pesquisa tem como objetivo fazer uma análise socioambiental da planície fluvial do referido rio, levando em consideração os aspectos climáticos, geomorfológicos, pedológicos e fluviais.

\footnotetext{
${ }^{1}$ Francisca Nathalia Silva Mesquita, bolsista PIBIC/CNPq, Centro de Ciências Humanas/ Curso de Geografia/Laboratório de Estudos Ambientais (LEA), Universidade Vale do Acaraú, Sobral - CE, Brasil;

2Maria Clévia Sousa, Bolsista PBU/UVA, Centro de Ciências Humanas/ Curso de Geografia/Laboratório de Estudos Ambientais (LEA), Universidade Vale do Acaraú, Sobral - CE, Brasil;

${ }^{3}$ Isorlanda Caracristi, Profa. Dra. do Curso de Geografia da Universidade Estadual Vale do Acaraú- (UVA) CE, Brasil. Coordenadora do Laboratório de Estudos Ambientais (LEA).

${ }^{4}$ professora Dra. Simone Diniz, Centro de Ciências Humanas, Laboratório de Estudo Ambientais (LEA), Universidade Vale do Acaraú.
} 
O rio Acaraú nasce na Serra das Matas, no município de Monsenhor Tabosa-CE, e deságua no Oceano Atlântico, na cidade de Acaraú/CE, com uma área de 14.500 km² e com $320 \mathrm{~km}$ até a foz. Os seus principais afluentes se encontram na margem direita (rios dos Macacos, Groaíras, Jacurutu e Sabonete) e, na margem esquerda, o de maior destaque é o rio Jaibaras. O rio Acaraú drena em torno de 30 municípios, dentre eles o de Santana do Acaraú, que é o recorte da referida pesquisa. Ele apresenta uma capacidade de acumulação de águas superficiais de 1.443.763.000 bilhão de $\mathrm{m}^{3}$, num total de 14 açudes públicos gerenciados pela Companhia de Gestão dos Recursos Hídricos (COGERH, p. 10).

A bacia hidrográfica do rio Acaraú é a segunda maior do Ceará, com quase $15.000 \mathrm{Km}^{2}$ de extensão, e $315 \mathrm{~km}$ de comprimento na direção predominante norte-sul, num formato que lembra um mapa da América do Sul invertido. Sua bacia hidrográfica abrange um total 30 municípios, numa área de $14.500 \mathrm{~km}^{2}$, o que representa aproximadamente $10 \%$ da área do Estado.

Nela estão construídos alguns dos mais importantes açudes cearenses: o Edson Queiroz, em Santa Quitéria; o Forquilha, no município de mesmo nome; o Aires de Sousa (ou Jaibaras), em Sobral; além do Paulo Sarasate (ou Araras), que está construído sobre o leito do rio Acaraú e cuja barragem está localizada no limite dos municípios de Varjota, Pires Ferreira e Santa Quitéria. São os seguintes municípios banhados pelo rio principal dessa bacia: 1) Alto curso: Monsenhor Tabosa, Tamboril, Catunda, Hidrolândia, Pires Ferreira, Ipu, Ipueiras, Nova Russas, Guaraciaba do Norte, Reriutaba, Ibiapina, Graça, Pacujá e Mucambo; 2) Médio Curso: Santa Quitéria, Cariré, Groaíras, Sobral, Meruoca, Alcântara, Forquilha Massapê, Santana do Acaraú e Varjota; 3) Baixo Curso: Morrinhos, Marco, Cruz, Bela Cruz e Acaraú. Estima-se que haja uma população próxima a 1 milhão de habitantes, distribuída em áreas de serra, sertão e litoral. (Plandesva, p. 08).

Em fevereiro de 2005, foi criado, como consequência do Decreto Estadual no 27.647, de dezembro de 2004, o Comitê da Bacia Hidrográfica do Acaraú-CBH Acaraú. Trata-se de um órgão colegiado, de caráter consultivo e deliberativo. É constituído por 40 instituiçõesmembras, estando estas distribuídas nos seguintes segmentos: Poder Público Municipal (8), Poderes Públicos Estadual e Federal (8), Usuários (12) e Sociedade Civil - 12 instituições. Com sede na cidade de Sobral, a CBH Acaraú vem cuidando de forma minuciosa das peculiaridades dessa bacia. 
No início do século XX, foi construído o açude Paulo Sarasate (Araras), que permitiu a perenização do rio, garantindo, a partir de Varjota, a oferta de água o ano todo, fazendo com que muitas áreas das margens fossem desmatadas indiscriminadamente, cedendo lugar para a agricultura.

A bacia hidrográfica do rio Acaraú e seu tributário, o Jaibaras, comandam o sistema hidrográfico da região, juntamente com o rio Coreaú, que tem sua nascente localizada no município de Ubajara-CE, cujos divisores são representados pelos níveis elevados do maciço da Meruoca-Rosário. O rio Jaibaras encontra-se com o rio Coreaú pela margem esquerda, pouco ao sul da cidade de Sobral, de modo que os riachos situados ao sul dessa confluência deságuam no Jaibaras, enquanto os do norte o fazem diretamente no Acaraú-CE.

Devido à predominância do período seco sobre o chuvoso, os rios apresentam-se intermitentes e a concentração dessa hidrografia ocorre em função da declividade e da natureza do terreno. No trecho de formação cristalina, o relevo se apresenta aplainado e a impermeabilidade das rochas permite o desenvolvimento de uma drenagem de padrão dentrítico. Já nas áreas sedimentares, a hidrografia é mais perfeita, devido à maior permeabilidade das rochas e dos cursos d'água paralelos.

Quanto à morfologia dos canais fluviais, no caso específico do município de Santana do Acaraú, o canal é anastomosado, com sucessivas ramificações e posteriores reencontros ao longo de seu curso, com a separação de pequenas ilhas, com drenagem exorreica segundo o padrão de escoamento.

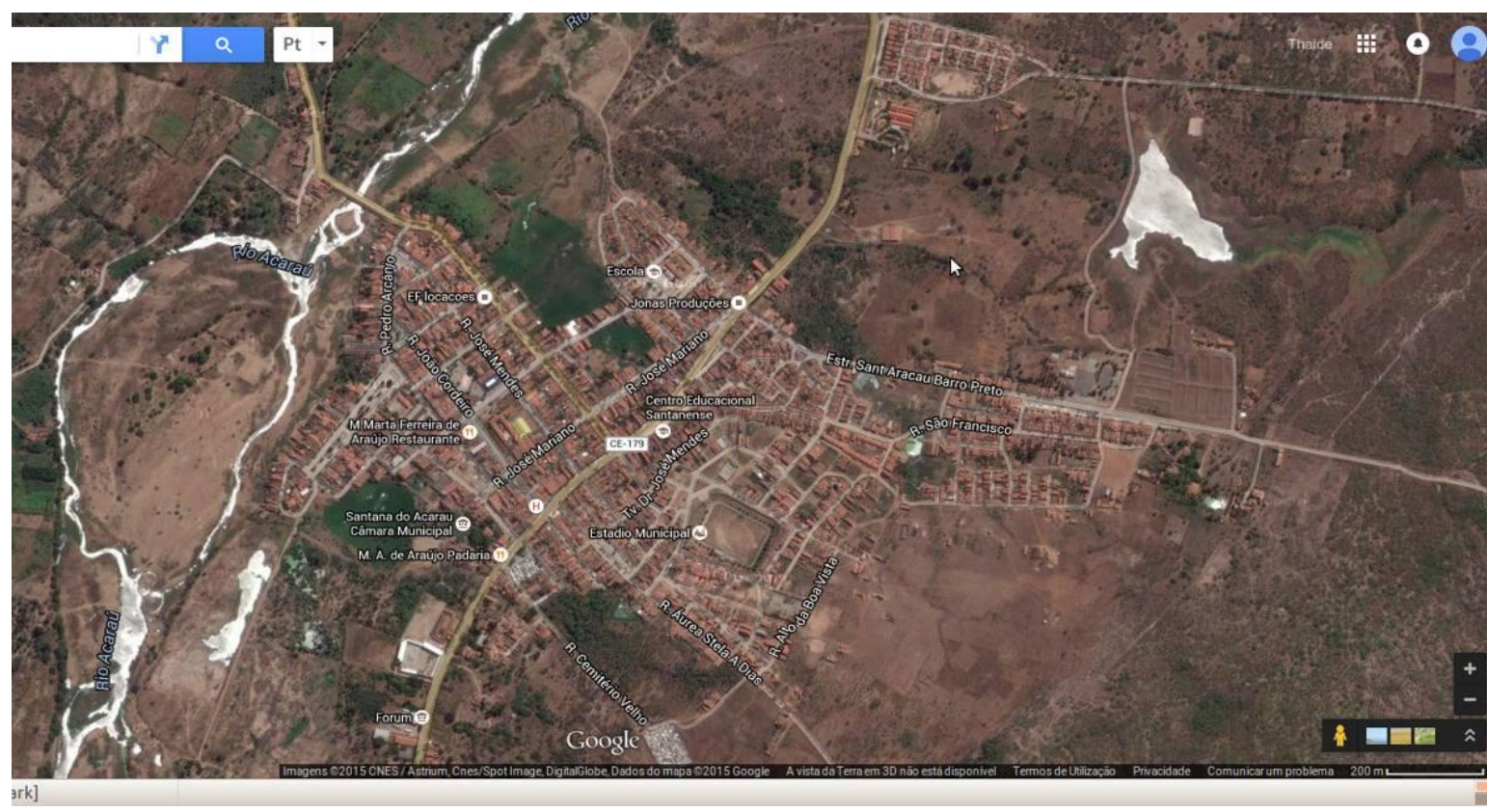


Fig. 01 - Localização da Cidade de Santana do Acaraú - CE. Adaptada do Google Maps 2015, figura representativa do quadrante da área de estudo, localizado na cidade de Santana do Acaraú-CE

\section{Caracterização da área de estudo}

\section{Clima}

O conceito de clima adotado é aquele que o define como send climatologia, verifica-se a imprescindibilidade da abordagem dinâmica à compreensão dos sistemas climáticos em sua relação com o espaço geográfico”. (MUNIZ, CARACRISTI, 2015, p. 07).

O clima semiárido é responsável principalmente por condicionantes da dinâmica ambiental ao longo do rio Acaraú. É importante citar que as temperaturas médias são consideradas elevadas.

Geralmente, situando-se entre $25^{\circ} \mathrm{C}$ e $29^{\circ} \mathrm{C}$, resultam em índices de evapotranspiração superiores a $1.000 \mathrm{~mm}$ anuais. A pluviometria é variável espacialmente, situando-se, em geral, entre $500 \mathrm{~mm}$ e $1.000 \mathrm{~mm}$ anuais nas áreas periféricas e zonas mais úmidas, e variando de $500 \mathrm{~mm}$ a $700 \mathrm{~mm}$ entre áreas do Sertão Central, onde o período seco se estende por até nove meses, (BEZERRA, 1990, p. 180).

Por isso o clima é um fator muito significativo para a caracterização da área de estudo, pois engloba todos os aspectos relacionados ao médio curso do rio Acaraú.

\section{Geologia}

A litologia da área estudada é formada principalmente por rochas do embasamento cristalino de idade pré-cambriana, composta por gnaisses, xistos, filitos, anfibolitos e ardósias (DINIZ, 2008, p. 357).

\section{Geomorfologia}

A área pesquisada apresenta morfologia variada composta por planície fluvial, maciços residuais e depressão sertaneja. As planícies fluviais representam típicas formas de deposição fluvial que oferecem melhores condições de utilização agrícola.

A planície fluvial do rio Acaraú, juntamente com a do rio Jaguaribe, apresenta as mais largas planuras fluviais do Estado, alargando-se no baixo curso do rio. Tanto as planícies flúvio-lacustres quanto as planícies fluviais, com destaque para os principais tributários do médio curso do rio Acaraú, são formas de acumulação gerada por processos fluviais. 
As várzeas são típicas das planícies fluviais e são inundadas no período chuvoso, por isso o leito maior é ocupado em seu período seco pela agricultura de vazante, fato verificado também em seu leito excepcional. Apresenta mata ciliar de carnaúba (Coperníciacerifera), assentada sobre depósitos aluviais arenoargilosos, chegando a compor a várzea baixa. As várzeas altas são as fácies abrigadas das inundações.

\section{Pedologia}

São encontrados na área de estudo Neossolos Flúvicos, Luvissolos e Argissolos Vermelho-Amarelo. Os Luvissolos estão normalmente associados aos Neossolos Litólicos e Argissolos Vermelho-Amarelos, em áreas de relevo plano suavemente ondulado na depressão sertaneja, sob litotipos anfibolitos e gnáissico-migmatíticos. Por isso são considerados solos minerais com material parental composto por saprólitos de rochas pré-cambrianas, com características de não hidromórficos, com horizonte B textural, argila de alta atividade, provocando fendilhamentos durante as secas.

Os Argissolos Vermelho-Amarelos são solos minerais não hidromórficos, com horizonte $\mathrm{A}$ ou E contíguos ao B textural não plíntico, argila de alta ou baixa atividade e teores de ferro inferiores a $11 \%$. São encontrados em todos os tipos de relevo, desde o plano até o montanhoso. Desenvolvem-se a partir de sedimentos da Formação Barreiras e rochas do Pré-Cambriano. Eventualmente, podem ocorrer fragmentos rochosos. Sua coloração predominante é vermelho-amarelado, podendo conter tons bruno-avermelhados e em menor expressão.

Em termos de fertilidade natural, apresentam-se com média a alta fertilidade (Argissolos Vermelho-Amarelos Eutróficos) ou média a baixa (distróficos). Predominam os da classe de eutróficos, com valores de saturação de bases superiores a $50 \%$ e pequena presença de minerais primários facilmente decomponíveis. Os Neossolos Flúvicos são derivados de sedimentação fluvial recente (Holoceno) e pouco desenvolvidos, provenientes de deposição fluvial, apresentando sequência de horizontes A-C, mas somente horizonte A diferenciado, acompanhado de camadas estratificadas sem relação pedogenética entre si. Esse horizonte normalmente é fraco, mas também ocorre moderado e chernozênico (com maiores teores de carbonato de cálcio). Já os horizontes subjacentes ao A variam muito em composição, granulometria distinta e sem disposição preferencial, sendo mosqueados quando imperfeitamente drenados. Estão distribuídos ao longo das planícies do médio curso do rio Acaraú, às vezes associados aos Planossolos. 


\section{Vegetação}

Conforme Fernandes \& Bezerra (1990, p.100) “o médio curso do rio Acaraú está totalmente inserido no contexto do semiárido nordestino, limitado pela Província Nordestina ou das Caatingas, correspondendo à Zona ou ao Domínio das Caatingas". É importante mencionar a importância da cobertura vegetal da caatinga, pois ela está presente no médio curso do rio Acaraú, bem como em todo o Estado do Ceará. Descrita por Fernandes (1990, p.100), ela possui uma "vegetação predominantemente caducifólia, sobre um solo raso e quase sempre pedregoso, de extrema deficiência hídrica durante grande parte do ano".

A mata aberta clara surgiu do termo de origem indígena que se opõe às matas fechadas e escuras. Também são encontradas outras vegetações no médio curso, como são descritas por Figueiredo (1997, p.23): "Das onze unidades fitoecológicas para o Estado do Ceará, oito são ocorrentes na área da bacia e duas outras lhe são contíguas".

A caatinga é uma vegetação com predominância no vale, mas também são encontradas vegetações de carnaúba e mangue, com grande ocorrência de cactáceos e outras espécies xerófitas, que normalmente estão localizadas nas zonas áridas. Já os ecossistemas do manguezal do rio Acaraú possuem vegetação arbórea padronizada.

Conforme Fernandes (1990),

Pode ser classificada como Floresta Perenifólia Latifoliada Paludosa Marítima. A flora dos manguezais encontrada no estuário do Rio Acaraú, assim como nos demais manguezais cearenses, é representada por um conjunto taxonômico de quatro famílias botânicas e cinco gêneros, das 13 famílias e cerca de 20 gêneros que constituem os mangues em todo o mundo. ( p.100)

\section{METODOLOGIA}

Este trabalho é uma forma de divulgação dos resultados de uma análise socioeconômica que está em desenvolvimento sobre a planície fluvial do médio curso do rio Acaraú, na cidade de Santana do Acaraú, e que se baseia na seguinte metodologia de pesquisa: a) levantamento e revisão bibliográfica; b) entrevista com representantes ambientais do; c) levantamento de campo realizado no leito do rio, para demarcação da área de estudo; d) utilização de mapas e de imagens digitais de climatologia, geologia, geomorfologia e pedologia, desenvolvidos em ambiente SIG. 


\section{RESULTADOS E DISCUSSÕES}

A área estudada apresentou resultados preocupantes em relação ao uso e à ocupação inadequada do solo. O desmatamento das matas ciliares para a prática da agricultura e o assoreamento visível é agravante e contribuiu para a situação alarmante na qual o médio curso do rio Acaraú se encontra hoje. São consequências das práticas realizadas no interior do leito do rio, tais como a contaminação da água através resíduos de produtos de limpeza, esgotos depositados diretamente no leito do rio sem tratamento adequado, destacando também a desordem no que se refere ao lixo jogado no leito e em suas margens.

Em Santana do Acaraú, as contribuições sociais no médio curso do rio Acaraú são imensuráveis. Fazendo um retrospecto sobre elas, continua eternizado na memória dos santanenses e visitantes o inesquecível banho no médio curso do rio Acaraú, nos festejos da padroeira da cidade, comemorado no mês de julho. Infelizmente, a situação na qual o médio curso do rio Acaraú se encontra hoje é deplorável. Considerando os períodos de estiagem que enfrentamos ao longo dos últimos anos, há outro agravante que resultou no grande impacto ambiental negativo do médio curso do rio Acaraú: tais impactos são visíveis em toda a área estudada, como o assoreamento e o desmatamento das matas ciliares, e resíduos sólidos lançados no leito do rio (Figuras 2, 3 e 4).

O estudo realizado em 2008 pelo Plano de Desenvolvimento Sustentável do Vale do Acaraú - PLANDESVA foi um dos trabalhos que já diagnosticavam essas problemáticas, as quais culminaram na realidade com a qual nos deparamos nos dias atuais.

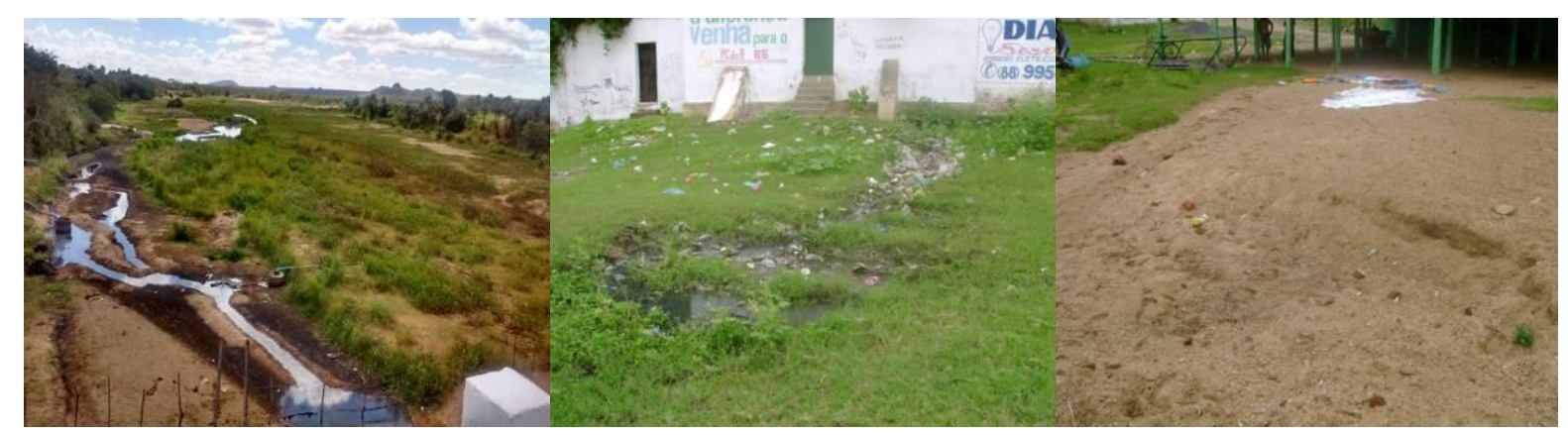

Figuras 2, 3 e 4. Manoelzinho Canafístula. 2014/2015

\section{CONSIDERAÇÕES FINAIS}

A presente análise do médio curso do rio Acaraú nos remeteu a diversas reflexões e discussões acerca da planície fluvial dele em nosso município, uma vez que ele contribui e continua contribuindo diretamente para a sobrevivência da população local. Em pesquisas 
realizadas com as lideranças ambientais do município, revelou-se falta de planos de manejo sustentável voltados à defesa do médio curso do rio Acaraú.

Houve diversas campanhas de conscientização e planos de intervenção elaborados junto ao poder público em prol de políticas públicas que favorecessem o médio curso do rio Acaraú, mas praticamente nada de eficaz foi feito.

Praticamente a única intervenção feita no sentido de mostrar a importância do rio é a tradicional Marcha do Vale, que, em 2014, esteve em sua $5^{a}$ edição. Tal evento é organizado pela Diocese de Sobral, devido aos festejos religiosos que articulam toda a comunidade em geral através de suas paróquias para a marcha.

A Marcha propõe reflexões acerca do médio curso do rio Acaraú e, ao final do encontro, é feito um fórum com a elaboração de planos e metas a serem executados junto ao poder público em defesa do rio, nas cidades abrangidas pela Diocese que são banhadas por ele. Conforme pudemos comprovar nas figuras (2, 3 e 4) presentes nos resultados e discussões no recorte da área em estudo, é visível o descaso em relação ao lixo lançado no leito do rio, impactando nas margens do médio rio. Todos esses fatores promovem a proliferação de insetos e a contaminação do aquífero, causando doenças de pele e outras epidemias.

A retirada da mata ciliar - como a grande quantidade de retirada de areia, dentre outros - é um fator agravante, cau sando compactação do solo, das áreas ribeirinhas e elevação da temperatura, gerando ainda modificações no sistema natural da região estudada. Uma possibilidade iminente urgente é o desaparecimento de espécies de vegetais e animais, como peixes, aves silvestres, vegetação da caatinga, vegetações ribeirinhas como a Carnaúba, espécie natural necessária para minimizar tal problemática, aplicando práticas conservacionistas sustentáveis.

\section{REFERÊNCIAS}

COGERH - Companhia de Gestão dos Recursos Hídricos. Comitê da Bacia Hidrográfica do Acaraú. Disponível em: <http://portal.cogerh.com.br/eixos-deatuacao/gestaoparticipativa/comites-de-bacias-hidrograficas/comite-da-bacia-hidrografica-doacarau>. Acesso em: 25 ago. 2015

DINIZ, S.F.; MOREIRA, C. A.; CORRADINI, F.A. Susceptibilidade erosiva do baixo curso do rio Acaraú-Ce. Geociências (Rio Claro. Online), v. 27, p.355-367, 2008. 
FERNARDES, A. Temas Fisiográficos. Fortaleza ; Stylus Comunicações, 116 p.,1990.

FIGUEIREDO, MA. Vegetação. Altas do Ceará. Instituito de Planejamento do Estado do Ceará Fortaleza, p.24-25,1997.

FERNARDES, A. \& BEZERRA, P. Estudo fitogeográfico do Brasil, Stylus Comunicações, Fortaleza, 205 p.,1990.

Instituto de pesquisas e estratégia econômica do Ceará. Perfil Básico Municipal - Santana do Acaraú.

MUNIZ, G.L.; ISORLANDA, Caracristi. Urbanização, conforto térmico e análise sazonal microclimática da cidade de Sobral(CE), Revista da Casa da Geografia de Sobral/CE, v. 17, n. 1, p. 4-17, Mar. 2015. Edição Especial, http://uvanet.br/rcgs. ISSN 1516-7712 @ 1999, Universidade Estadual Vale do Acaraú. Todos os direitos reservados.

NAKASU, Licurgo. Plandesva - Plano de Desenvolvimento Sustentável do Vale do Acaraú. Sobral. 2008.

Recebido em: 14/08/2016

Aceito para publicação em: 01/10/2016 